Biochimica et Biophysica Acta, $572(1979) 519-530$

(C) Elsevier/North-Holland Biomedical Press

BBA 57334

\title{
A COMPARISON OF ACYL-OXYESTER AND ACYL-THIOESTER SUBSTRATES FOR SOME LIPOLYTIC ENZYMES
}

\author{
A.J. AARSMAN and H. VAN DEN BOSCH \\ Laboratory of Biochemistry, Padualaan 8, De Uithof, 3508 TB Utrecht (The Netherlands)
}

(Received August 3rd, 1978)

Key words: Acyl-oxyester; Acyl thioester; Lipolytic enzyme; Phospholipid; (Kinetics)

\section{Summary}

1. A comparison of 2-hexadecanoylthio-ethane-1-phosphocholine and 3hexadecanoylthio-propane-1-phosphocholine and their oxyester counterparts as substrates for some lipoly tic enzymes was made.

2 . The critical micelle concentration and the transition temperature of the synthetic substrates were compared with the values for 1-hexadecanoyl-snglycero-3-phosphocholine.

3. All above-mentioned compounds were deacylated by lysophospholipases. Phospholipase $\mathrm{A}_{2}$ hydrolyzed only the acyl- sulfur- and oxygenester bond in 2-hexadecanoyl-ethane-1-phosphocholine.

4. Kinetic parameters, $K_{\mathrm{m}}$ and $V$, for hydrolysis of these substrates were determined. $K_{\mathrm{m}}$ values for thioester substrates were 5-10-fold lower than for the corresponding oxyesters. Maximal hydrolysis rates were $2-5$ times higher for the thioesters.

5 . Hydrolysis of thioesters by phospholipase $\mathrm{A}_{2}$, lipase and lysophospholipase was shown to proceed by an S-acyl cleavage mechanism.

6 . Beef liver lysophospholipase II was rapidly and stoichiometrically inactivated by diisopropylfluorophosphate and bis(p-nitrophenyl) phosphate. Inactivation by the latter inhibitor showed burst-like kinetics.

7. Attempts to show burst-kinetics during the pre-steady state hydrolysis of 2-hexadecanoylthio-ethane-1-phosphocholine by lysophospholipase II were negative. These results are interpreted to indicate that a step prior to deacylation of the enzyme is rate-determining.

\section{Introduction}

Previously we have reported on the synthesis of substrate analogs for lipolytic enzymes in which the acyl oxyester bond was replaced by an acylthioester 
bond [1]. Lipase, phospholipase $A_{2}$ and lysophospholipases were found capable of hydrolyzing acylthioester bonds in their respective substrates $[1,2]$. Spectrophotometric measurement of the release of thiol groups during hydrolysis in the presence of chromogenic thiol reagents provided a convenient and sensitive assay method. This approach was not limited to purified enzymes but could also be used for lysophospholipase detection in crude subcellular fractions [3] or during enzyme purification [4]. In the present paper we have made a further comparison of the thioester substrates and their oxyester counterparts with respect to some physico-chemical properties and the kinetics constants $K_{\mathrm{m}}$ and $V$ for hydrolysis by purified lysophospholipases and phospholipase $A_{2}$. The site of thioester bond cleavage was determined by measurement of thiol groups in the acyl and alkyl products. In the presence of substrate quantities of lysophospholipase the thioester substrates were used in a search for an acyl-enzyme intermediate in the cataly tic process.

\section{Materials and Methods}

\section{Syntheses of substrates}

The thioester substrates were synthesized as described previously [1]. The structural formulae of 2-hexadecanoylthio-ethane-1-phosphocholine (thioglycollecithin, I) and 3-hexadecanoylthio-propane-1-phosphocholine (thiodeoxylysolecithin, II) are depicted in Scheme I. The corresponding oxyester structures will be indicated by Roman numbers III and IV, respectively.

The ${ }^{14} \mathrm{C}$-labelled oxyester analog of thioglycollecithin was synthesized by<smiles>[R]C(=O)SCCOP(=O)([O-])OCC[Si+](C)(C)C</smiles><smiles>[R]C(=O)SCCCOP(=O)([O-])OCC[N-]C</smiles>

Scheme I. Structural formulae of substrates. I, 2-hexadecanoyithio-ethane-1-phosphocholine (thioglycollecithin). II, 3-hex adecanoylthio-propane-1-phosphocholine (thiodeoxylysolecithin). The oxyester analogs of I and II will be indicated by Roman numerals III and IV, respectively. $R_{I}$ stands for $-\left(\mathrm{CH}_{2}\right)_{14} \mathrm{CH}_{3}$. 
acylation of the $\mathrm{CdCl}_{2}$ adduct of ethyleneglycolphosphocholine with $\left[1{ }^{14} \mathrm{C}\right]$ palmitoyl chloride according to the method of Baer and Buchnea [5], except that the reaction was carried out in dry ether [6]. The ethyleneglycolphosphocholine was prepared by the method of Yabusaki and Wells [7] and was a generous gift of $\mathrm{Mr}$. R. Dijkman from this laboratory. The $2-\left[1-^{14} \mathrm{C}\right]$ hexadecanoylthio-ethane-1-phosphocholine (oxyglycollecithin, III) obtained in this way had a specific radioactivity of $1.2 \cdot 10^{8} \mathrm{dpm} / \mathrm{mmol}$. The oxyester analog of thiodeoxylysolecithin was synthesized in the same way as the thiocster derivative [1] starting with the acylation of 1,3 propanediol with $\left[1-{ }^{14} \mathrm{C}\right]$ palmitoyl chloride. The so-formed $3-\left[1-{ }^{14} \mathrm{C}\right]$ hexadecanoyloxy-propane-1-phosphocholine (oxydeoxylysolecithin, IV) had a specific radioactivity of $1.2 \cdot 10^{8} \mathrm{dpm} / \mathrm{mmol}$. 1-Hexadecanoyl-sn-glycero-3-phosphocholine was prepared as described previously [8].

\section{Enzymes}

Lysophospholipases I and II (EC 3.1.1.5) from beef liver were purificd as described by de Jong et al. [8]. Phospholipase $A_{2}$ (EC 3.1.1.4) from porcine pancreas was kindly donated by Dr. H.M. Verheij from this laboratory; porcine pancreatic lipase (EC 3.1.1.3) was a generous gift from Dr. R. Verger (Marseille, France).

\section{Enzyme assays}

The rate of thioester substrate hydrolysis was measured in a double-beam spectrophotometer (Varian, Model 635) with a temperature-controlled cell compartment. Lysophospholipase assays were done in $20 \mathrm{mM}$ potassium phosphate buffer ( $\mathrm{pH}$ 7.5), $1 \mathrm{mM}$ 5,5'-dithiobis(2-nitrobenzoic acid). Phospholipase $\mathrm{A}_{2}$ activity was assayed in $0.2 \mathrm{M}$ Tris/maleic acid buffer (pH 7.5), $5 \mathrm{mM} \mathrm{CaCl}_{2}$,

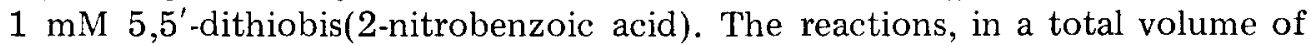
$1 \mathrm{ml}$, were initiated by addition of a solution of pure enzyme in water to the sample cuvette; a similar volume of water was added to the reference cuvette. A molar extinction coefficient of $12800 \mathrm{l} \cdot \mathrm{mol}^{-1} \cdot \mathrm{cm}^{-1}$ for the thionitrobenzoic acid anion was used to calculate nmol substrate hydrolysed. When incubations were done at $\mathrm{pH}$ values lower than $7.0,4,4^{\prime}$-dithiodipyridine with a molar extinction coefficient of $19800 \mathrm{l} \cdot \mathrm{mol}^{-1} \cdot \mathrm{cm}^{-1}$ for the 4-thiopyridone [9], was used as the chromogenic reagent. When the rate of hydrolysis of the oxyesters was compared with that of the thioesters, the ${ }^{14} \mathrm{C}$-labelled oxyesters were also

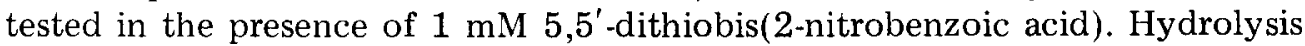
rates were calculated from the fatty acid radioactivity present in the heptanelayer after a modified Dole extraction and the known specific radioactivity of the substrates as described previously [8].

\section{Analyses}

Thin-layer chromatography was performed on silica gel $\mathrm{G}$ plates. Phospholipids were separated with $\mathrm{CHCl}_{3} / \mathrm{CH}_{3} \mathrm{OH} / \mathrm{H}_{2} \mathrm{O}(60: 40: 10, \mathrm{v} / \mathrm{v})$, whereas neutral lipids were separated with petroleum ether (bp 40-60 ${ }^{\circ} \mathrm{C}$ )-diethyl ether/ formic acid $(60: 40: 1.5, \mathrm{v} / \mathrm{v})$. Water soluble hydrolysis products were chromatographed with $\mathrm{CH}_{3} \mathrm{OH} / \mathrm{H}_{2} \mathrm{O}(7: 3, \mathrm{v} / \mathrm{v})$, as described by Yabusaki and Wells [7]. 
Radioactivity measurements were carried out in a toluene scintillation mixture containing $7 \mathrm{~g} / \mathrm{l}$ PPO and $0.3 \mathrm{~g} / \mathrm{l}$ dimethyl POPOP in a Packard Model 3003 liquid scintillation spectrometer.

Lipid phosphorus was determined by the method of Chen et al. [10], after ashing by the procedure of Ames and Dubin [11].

Critical micelle concentrations were determined in $0.1 \mathrm{M} \mathrm{NaCl}$ with the surface tension technique, using the Wilhelmy plate [12].

Differential scanning calorimetry experiments were performed as described by van Dijck et al. [13].

\section{Chemicals}

$\left[1-{ }^{14} \mathrm{C}\right]$ Palmitic acid and $\left[1-{ }^{14} \mathrm{C}\right]$ butyric acid were obtained from Radiochemical Centre, Amersham, U.K. Thiol reagents, 5,5'-dithiobis(2-nitrobenzoic acid), 4,4'-dithiodipyridine and diisopropylfluorophosphate were purchased from Aldrich, Beerse, Belgium. $p$-Nitrophenylacetate was a product of Merck AG, Darmstadt, F.R.G. Bis-( $p$-nitrophenyl)phosphate was obtained from Sigma, St. Louis, U.S.A.

\section{Results and Discussion}

Fig. I shows the chromatographic behaviour of the synthetic compounds. Due to the absence of a free hydroxylgroup the substrate analogs (see Scheme I) run somewhat faster than the 1-palmitoyl-sn-glycero-3-phosphocholine, but no differences between oxyester and thioester compounds can be detected. The thin-layer chromatogram demonstrates the purity of the synthetic products. The differential scanning calorimetry measurements depicted in Fig. 2 indicate a single transition peak for all compounds. The transition temperatures and

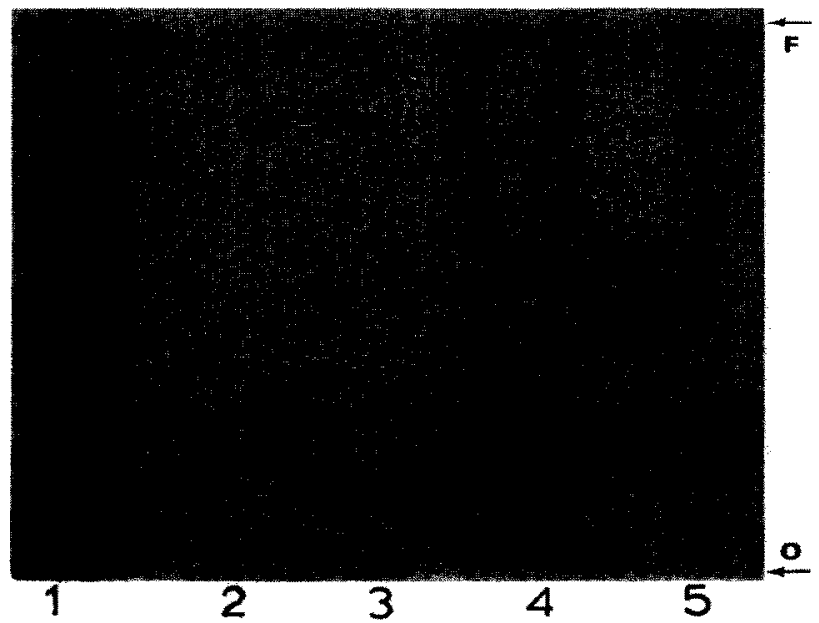

Fig. 1. Thin-layer chromatogram os substrates. Two concentrations of each substrate were applied to the plate developed in $\mathrm{CHCl}_{3} / \mathrm{CH}_{3} \mathrm{OH} / \mathrm{H}_{2} \mathrm{O} / \mathrm{NH}_{4} \mathrm{OH}(90: 54: 5.5: 5.5, \mathrm{v} / \mathrm{v}$ ). Spuls were visualized wilh a phosphor-spray reagent [14]. The same picture was obtained after staining with $I_{2}$ vapour or charring with $50 \% \mathrm{H}_{2} \mathrm{SO}_{4}$. 1, thioglycollecithin (I); 2 , oxyglycollecithin (III); 3, 1-acyllysolecithin; 4, thiodeoxyly * solecithin (II) and 5 , oxy deoxylysolecithin (IV). O, origin; F, front. 


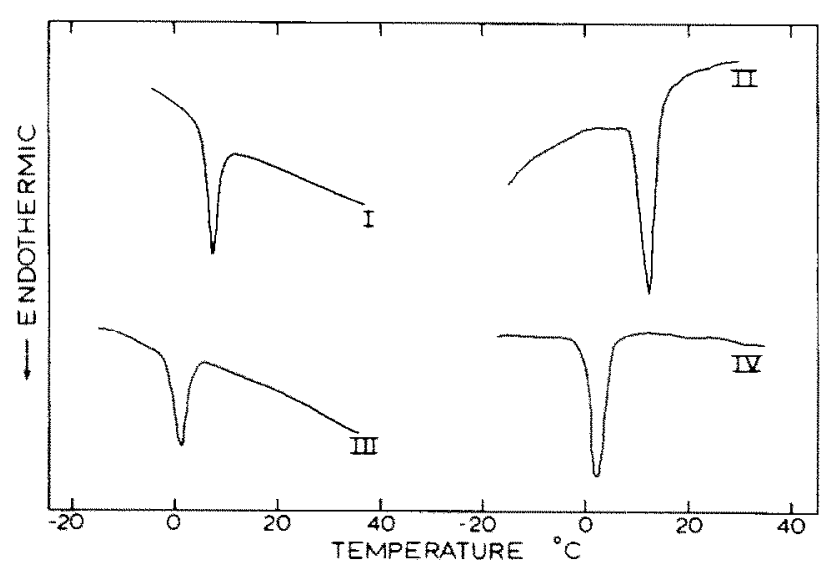

Fig. 2. Differential scanning calorimeter thermograms of substrates. Dried lipids were dispersed in $50 \mu 1$ $40 \mathrm{mM}$ Tris/acetate buffer $(\mathrm{pH} 7.5)$, ethyleneglycol $(1: 1, v / v)$. Roman numbers refer to the synthetic compounds as in legend of Fig. 1.

critical micelle concentrations of the compounds are listed in Table I. The transition temperatures of the thioester compounds appear to be $8^{\circ} \mathrm{C}$ above that of the corresponding oxyesters, but all are comparable with that of 1-palmitoyllysophosphatidylcholine. The observed transition temperature for the latter compound is in agreement with a literature value [15] although considerable lower than the value of $18.5^{\circ} \mathrm{C}$ reported by Stoffel et al. [16]. It should be noted, however, that these authors obtained the transition temperature indirectly from light scattering data.

The critical micelle concentrations of the thioester compounds are somewhat lower than for the oxyester counterparts. This is in line with the expected increase in hydrophobicity upon the O-S substitution. Likewise, the lack of a free hydroxylgroup in all substrate analogs results in a somewhat lower critical micelle concentration when compared with 1-acyllysophosphatidylcholine. The observed value for the latter compound agrees well with a recently reported value [17], although somewhat higher values up to $120 \mu \mathrm{M}$ have been published in the older literature $[18,19,20]$.

Both thioester substrates I and II when incubated with an excess of beef liver lysophospholipase $1 \mathrm{l}$ released $1.00 \pm 0.05 \mathrm{nmol}$ thiolgroups $/ \mathrm{nmol} \mathrm{P}_{\mathrm{i}}$ in the sub-

TABLE I

SOME PHYSICOCHEMICAL PARAMETERS OF THIOESTER AND OXYESTER ANALOGS OF LYSOPHOSPHATLDYLCHOLINE

\begin{tabular}{llc}
\hline Compound * & $\begin{array}{l}\text { Critical micelle concn. } \\
(\mu \mathrm{M})\end{array}$ & $\begin{array}{l}\text { Transition temperature } \\
\left({ }^{\circ} \mathrm{C}\right)\end{array}$ \\
\hline Thioglycollecithin (I) & $3.5-4.5$ & +5 \\
Oxyglycollecithin (III) & $5.5-6.5$ & -3 \\
Thiodeoxylysolecithin (II) & $2.5-3.5$ & +8 \\
Oxydeoxylysolecithin (IV) & $4.0-5.0$ & 0 \\
1-Acyl lysolecithin & $7.0-8.0$ & +3 \\
\hline
\end{tabular}

* All compounds are the palmitovl derivatives. 
TABLE II

KINETIC PARAMETERS FOR HYDROLYSIS OF THIOESTER AND OXYESTER SUBSTRATES BY LYSOPHOSPHOLIPASES AND PHOSPHOLIPASE A 2

$K_{m}(\mu \mathrm{M})$ and $V\left(\mathrm{nmol} \cdot \mathrm{min}^{-1} \cdot \mathrm{mg}^{-1}\right.$ ) values were obtained from Lineweaver-Burk plots. Slopes and intercepts of the resulting straight lines were ealculated by the method of least squares. Each value is the mean \pm S.D. from 3-5 expeximents. $V$ values for 1 ysuphuspholipase I (nean $L$ S.D. from $8-15$ experiments) were obtained by rate measurements at saturating substrate concentration $(0.2$ and $0.4 \mathrm{mM}$ substrate gave identical values).

\begin{tabular}{|c|c|c|c|c|c|}
\hline \multirow[t]{3}{*}{ Substrate } & \multicolumn{5}{|l|}{ Enzyme } \\
\hline & \multicolumn{2}{|c|}{ Phospholipase $A_{2}$} & \multicolumn{2}{|c|}{ Lysophospholipase II } & \multirow{2}{*}{$\begin{array}{l}\text { Lysophos- } \\
\text { pholipase I } \\
V\end{array}$} \\
\hline & $K_{\mathrm{M}}$ & $V$ & $K_{\mathrm{M}}$ & $r$ & \\
\hline Thioglycollecithin (I) & $10.0 \pm 0.6$ & $1210 \pm 50$ & $6.8 \pm 0.4$ & $1340 \pm 50$ & $3500+100$ \\
\hline Uxygly collecithin (II) & $120 \pm 20$ & $310 \pm 50$ & $30 \pm 2$ & $430 \pm 30$ & $820 \pm 50$ \\
\hline Thiodeoxylysolecithin (II) & - & 0 & $7.2 \pm 0.5$ & $1290 \pm 50$ & $1300 \pm 100$ \\
\hline Oxydeoxylysolecithin (IV) & - & 0 & $50 \pm 3$ & $600 \pm 40$ & $270 \pm 20$ \\
\hline 1-Acvllysolecithin & - & 0 & \pm 5 & $600+50$ & $700+100$ \\
\hline
\end{tabular}

strate. The $K_{\mathrm{m}}$ and $V$ values for the different substrates were measured for given enzyme preparations, thus allowing a direct comparison of the values obtained for oxyester and thioester compounds. The results are listed in Table II. As expected phospholipase $\mathrm{A}_{2}$ was active only on the glycollecithins, since these are the only substrates which possess the minimal structural requirements for this enzyme as put forward by de Haas et al. [21]. In general the results show that apparent $K_{\mathrm{m}}$ values for thioester substrates are 5-10 times lower than for the corresponding oxyester substrates. Such tighter binding of thioester substrates when compared with their oxygen counterparts has also been observed for acetylcholine esterase [22] and $\alpha$-chymotripsin [23] and has been ascribed to increased hydrophobicity upon O-S substitution providing additional binding strength [24]. This hydrophobicity effect was shown to become smaller the higher the hydrophobicity of the leaving group to begin with. Thus, the $K_{\mathrm{m}}$ value for $\alpha$-chymotrypsin catalyzed hydrolysis of acetylglycine thiolethylester was almost 10-fold lower than for acetylglycine ethylester [23], whereas $p$-nitrophenylacetate and -thioacetate had identical $K_{\mathrm{m}}$ values [25]. The fact that the leaving group in the substrates used in 'lable II consists of a hydrophilic group (see below) leads to the expectation of a rather pronounced lowering of the apparent $K_{\mathrm{m}}$ due to the O-S substitution as was experimentally observed. It can also be seen in Table II that the maximal rate of sulfur ester hydrolysis is $2-5$ times that of the corresponding oxygen esters.

The detection of thiol groups by chromogenic reagents offers a simple method to determine whether hydrolysis of the thioester bond proceeds by S-alkyl or S-acyl cleavage. Qualitatively this was done by applying aliquots of the incubation mixtures on silicagel thin-layer plates and spraying, after development, with a buffered alcoholic solution of 5,5'-dithiobis(2-nitrobenzoic acid) as described by Glaser et al. [26]. In no case thiol groups were detectable in the spot of released fatty acids, whereas the other products of hydrolysis gave bright yellow spots. When the hydrolysis products were separated into $\mathrm{H}_{2} \mathrm{O}$ - and $\mathrm{CHCl}_{3}$-soluble compounds, $\mathrm{SH}$-groups were found to be 
TABLE III

ACYL CLEAVAGE OF THIOESTER LINKAGES BY LIPOLYTIC ENZYMES

Substrates $(3 \mu \mathrm{mol})$ were incubated at $37^{\circ} \mathrm{C}$ for $30 \mathrm{~min}$ with the indicated enzymes. The reaction mixture was separated into water-soluble and chloroform-soluble components by the method of Bligh and Dyer [27]. Aliquots of both phases were used for identification of hydrolysis products by thin-layer chromatography and for free thiol determinations. Blank incubations without enzymes gave no free thiol groups, neither in the aqueous nor in the chloroform phase.

\begin{tabular}{llll}
\hline Substrate & Enzyme & \multicolumn{2}{l}{ Released thiol (\%) in } \\
\cline { 3 - 4 } & & Water layer & Chloroform layer \\
\hline Thioglycollecithin (I) & Phospholipase A & 92 & 8 \\
Thiodeoxylysolecithin (II) & Lysophospholipase II & 95 & 5 \\
Thiotributyrin & Lipase & 9 & 91 \\
\hline
\end{tabular}

distributed as indicated in Table III. For phospholipase $\mathrm{A}_{2}$ and lysophospholipase-catalyzed reactions it was established by using radioactive markers that the released fatty acids and the remainder of the substrate were quantitatively recovered in the $\mathrm{CHCl}_{3}$ layer. Thin-layer chromatography of the water layer showed that only deacylated products and no free fatty acids were present. In the lipase catalyzed reaction more than $90 \%$ of the thiol groups were recovered in the $\mathrm{CHCl}_{3}$ layer. Thin-layer chromatography of this layer showed that only tributyrin and dibutyrin were present. Control experiments with $\left[1{ }^{14} \mathrm{C}\right]-$ butyrate confirmed that this short chain acid remained in the water-layer during the extraction procedure. Thus, the data in Table III are compatible only with an acyl cleavage mechanism for the hydrolysis of thioester bonds by the listed enzymes. For phospholipase $A_{2}$ this result is in agreement with the mechanism of oxygen ester hydrolysis as deduced by Wells [28] from experiments using $\mathrm{H}_{2}{ }^{18} \mathrm{O}$. For the other enzymes no direct experimental evidence concerning the bond breaking mechanism of oxygen esters is available.

The most obvious mechanism compatible with acyl cleavage of ester bonds is the formation of an acyl-enzyme intermediate. Wells [28] has already provided evidence which would suggest that phospholipase $A_{2}$-catalyzed hydrolysis does not proceed via an acylenzyme intermediate. However, circumstantial evidence indicates that lysophospholipases belong to the class of serine hydrolases. For example, beef liver lysophospholipase II is rapidly and stoichiometrically inactivated by diisopropylfluorophosphate (Fig. 3A and B). Prevailing opinion indicates that serine hydrolases act via an acyl-enzyme intermediate and the minimal kinetic scheme to account for such a mechanism is given by Eqn. 1:

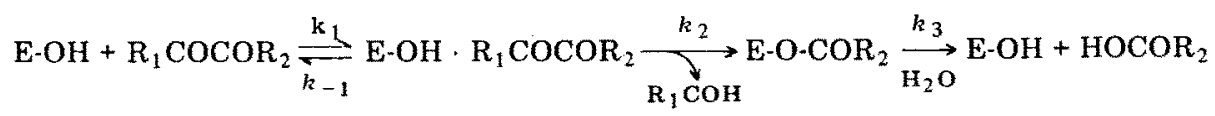

where $\mathrm{E}-\mathrm{OH}$ is enzyme with serine-OH, $\mathrm{R}_{1} \mathrm{CO}$ - is alkyl- and $\mathrm{R}_{2} \mathrm{OC}$ - is acyl part of the ester substrate, $\mathrm{E}-\mathrm{OH} \cdot \mathrm{R}_{1} \mathrm{COCOR}_{2}$ is the Michaelis complex ES and E-O$\mathrm{COR}_{2}$ is the acyl-enzyme intermediate which is deacylated to complete the hydrolytic reaction. In several cases $k_{2}$ has been found to be considerable larger 


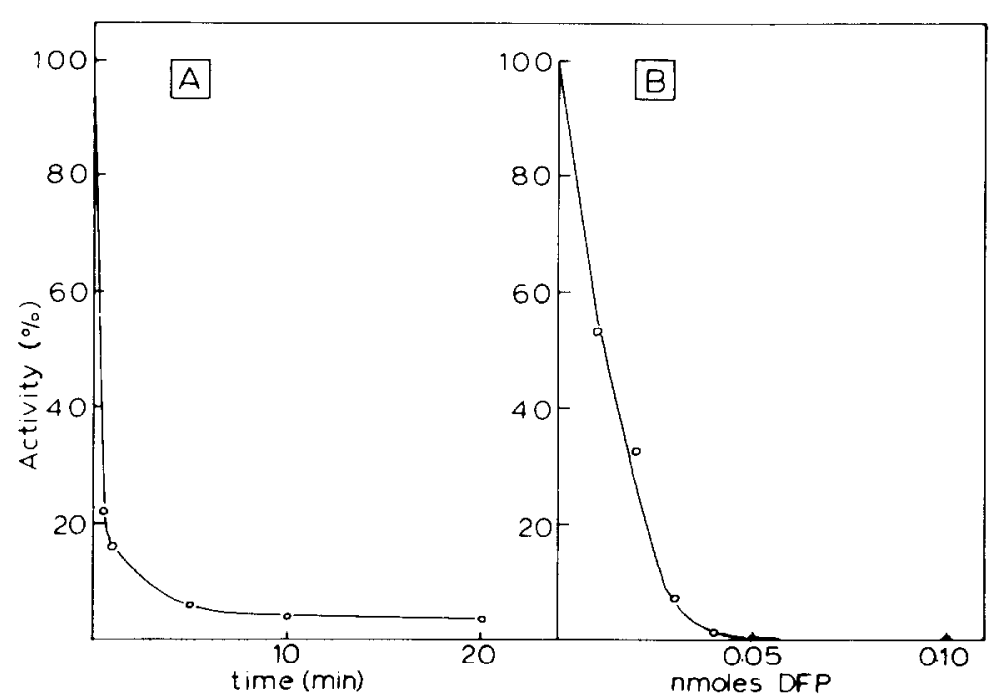

Fig. 3. Inactivation of lysophospholipase II activity by diisopropylfluorophosphate. A. Lysophospholipase II $(8.4 \mu \mathrm{g}, 0.14 \mathrm{nmol})$ were incubated with $0.14 \mathrm{nmol}$ diisopropylfluorophosphate in $0.37 \mathrm{ml} 80 \mathrm{mM}$ Tris/ $\mathrm{HCl}$ buffer $\left(\mathrm{pH} \mathrm{7.5)}\right.$ at $37^{\circ} \mathrm{C}$. At the indicated times, aliquots of $50 \mu 1$ were withdrawn for lysophospholipase assays. B. Enzyme $(2.4 \mu \mathrm{g}, 0.04 \mathrm{nmol})$ was incubated for $10 \mathrm{~min}$ at $37^{\circ} \mathrm{C}$ with the indicated amounts of diisopropylfluorophosphate in a total volume of $0.125 \mathrm{ml}$. Further conditions as in $\mathrm{A}$.

than $k_{3}$, thus allowing a rapid accumulation of the acyl-enzyme intermediate in the presteady state of the reaction. When the alkyl leaving group $\mathrm{R}_{1} \mathrm{COH}$ can be detected spectrophotometrically, as is the case for the $p$-nitrophenolate ion during $p$-nitrophenylester hydrolysis, the pre-steady state accumulation of the acyl-enzyme intermediate can be demonstrated directly by the initial burst in the release of the leaving group. This principle originally was shown to be valid for $\alpha$-chymotrypsin [29] and has been applied recently to pancreatic lipase [30]. Although for both enzymes compelling evidence is available which indicates that the same or at least part of the same active site is responsible for hydrolysis of $p$-nitrophenylesters and the natural substrates of these enzymes the formation of the acyl-enzyme intermediate during hydrolysis of the natural substrates has not been demonstrated. The availability of close substrate analugs for the lysophospholipases with an acyl thioester bond offered the possibility to search for the formation of an acyl-enzyme intermediate. The underlying principle is that the alkyl leaving group released during the formation of the acyl-enzyme intermediate in the hydrolysis of a thioester can be depicted as $\mathrm{R}_{1} \mathrm{CSH}$ and thus can be detected by a chromogenic thiol reagent. Provided the latter reacts fast enough with the thiol group it should be possible to get information about the rate-determining step in the reaction sequence outlined in Eqn. 1. If the rate-limiting step occurred after the formation of the covalent acyl-enzyne a burst of the product $\mathrm{R}_{1} \mathrm{CSH}$ would be obtained. On the other hand, if the rate-determining step took place prior to the formation of the acyl-enzyme intermediate no burst would be observed. Using substrate level concentrations of lysophospholipase II the steady state release of thiol groups during the hydrolysis of thioglycollecithin at the optimal $\mathrm{pH}$ of 7.5 for the enzyme was much too high to detect a possible burst. Also incubations at this 

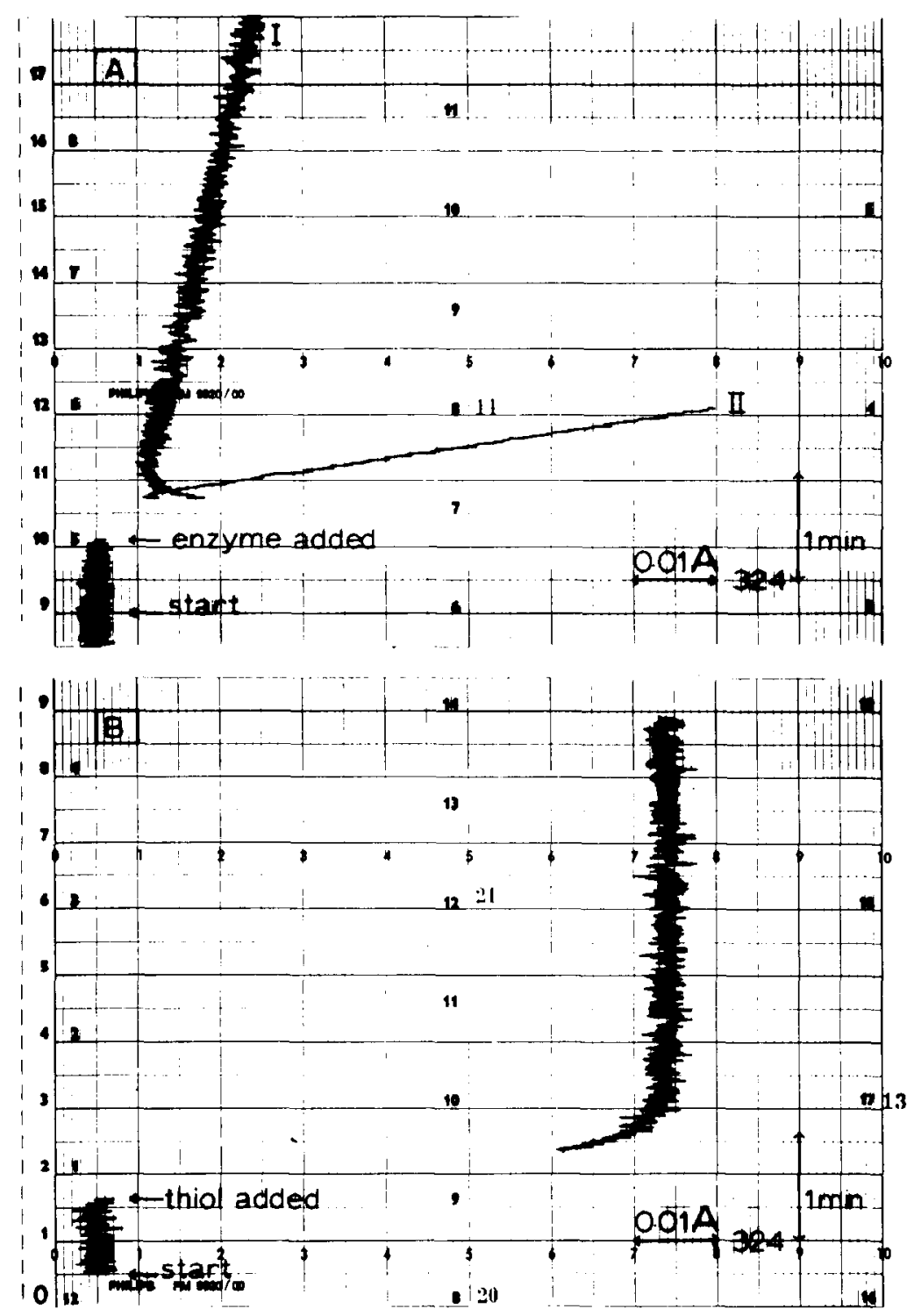

Fig. 4. Lack of burst kinetics for lysophospholipase II. (A) Lysophospholipase II (0.22 mg, $3.6 \mathrm{nmol}) \mathrm{was}$ incubated at $25^{\circ} \mathrm{C}$ with $100 \mu \mathrm{M}$ thiogly collecithin in $1 \mathrm{ml} 10 \mathrm{mM}$ sodium acetate buffer (pH 4.3) (curve I)

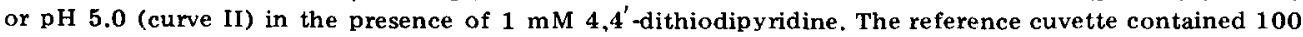
$\mu \mathrm{M}$ egg lysophosphatidylcholine. The theoretical intercept for a burst under these experimental conditions is $0.02 A_{324}$ per nmol enzyme. Thus, the expected intercept if a burst had occurred would have been $0.072 A_{324}$ units (compare B). Full scale deflection corresponds to $0.1 A_{324}$ unit. (B) Control

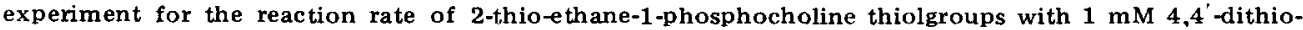
dipyridine at pH 4.3 and $25^{\circ} \mathrm{C}$. 2-thioethane-1-phosphocholine was prepared by incubation of thioglycollecithin with excess lysophospholipase II. Enzyme action was stopped by addition of diisopropylfluorophosphate (final concentration, $2 \mathrm{mM}$ ). The thiol concentration in this solution was determined with $5,5^{\prime}$ dithiobis(2-nitrobenzoic acid) at $\mathrm{pH}$ 7.5. An aliquot equivalent to $3.6 \mathrm{nmol}$ 2-thio-thane-1-phosphocholine was added to $1 \mathrm{ml} 10 \mathrm{mM}$ sodium acetate buffer ( $\mathrm{pH} 4.3$ ), $1 \mathrm{mM} \mathrm{4,4}$-dithiodipyridine. 
$\mathrm{pH}$ value in the presence of sodium deoxycholate to lower the steady-state hydrolysis rate gave no biphasic rate curves. When the $\mathrm{pH}$ of the medium was lowered to 5.0 or 4.3 the recorder tracings presented in Fig. $4 \mathrm{~A}$ were obtained. It is obvious that the extrapolation from steady state hydrolysis gives no indication for an initial burst reaction. The expected intercept if a burst had occurred with $3.6 \mathrm{nmol}$ of enzyme would have been 0.072 absorbance units. Several control experiments were carried out to verify our ability to measure a burst with the experimental techniques used. Firstly, when chymotrypsin and $p$-nitrophenylacetate were used the expected burst [29] was obtained. Secondly, the question as to whether the released thiolgroups reacted fast enough with the chromogenic reagent under the experimental conditions to detect a burst was investigated. The deacylated product of thioglycollecithin, i.e. 2-thio-ethane-1-phosphocholine, was prepared. An aliquot about equivalent to the amount which would be released assuming that a burst occurred in the experiment of Fig. 4A, was added to the cuvette. As can be seen in Fig. 4B this

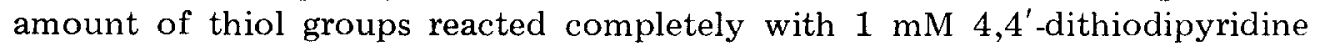
within about 30 s, i.e. fast enough to detect an initial burst if this occurred. The failure to observe burst kinetics in the experiment of Fig. $4 \mathrm{~A}$ must mean therefore that acylation of the enzyme rather than deacylation is rate-determining. This result agrees well with the earlier observation that the sulfur ester substrates are hydrolyzed at higher rates than the corresponding oxygen ester substrate (Table II). If deacylation would be rate-determining one would expect identical hydrolysis rates for thioester and oxyester compounds due to the fact that a common acyl-enzyme intermediate is formed from both substrates. This was in fact observed during studies of the chymotrypsin-catalyzed hydrolysis of $p$-nitrophenylacetate and $p$-nitrophenylthiolacetate [25,31]. With both substrates acylation of the enzyme was more rapid than deacylation and identical $k_{\text {cat }}$ values were observed due to rate-determining deacylation of a common acetyl-enzyme intermediate [25]. In contrast Chapus et al. [30] pointed out that $k_{\text {cat }}$ calculated for hydrolysis of dissolved triacetin by pancreatic lipase was 20 -times higher than that obtained with dissolved $p$-nitrophenylacetate, although the deacylation of the same acetyl intermediate should have been rate limiting in both cases. No explanation for this apparent discrepancy could as yet be offered. However, Zerner and Bender [32], in their sludies of chymotrypsin-catalyzed hydrolysis of acetyl-L-tryptophan ethyl ester and amide, assumed that deacylation of the intermediary acetyl-L-tryptophanyl-chymotrypsin proceeded at equal rates for both substrates. The deacylation of the acylated enzyme was rate-determining in the reaction with acetyl-L. tryptophan ethyl ester (as is the case with $p$-nitrophenylacetate), whereas in the reaction with the amide, the formation of acetyl-L-tryptophanyl-enzyme was rate-determining. Similarly, in the hydrolysis of $p$-nitrophenylacetate by horse liver aldehyde dehydrogenase, a step leading to the acyl-enzyme intermediatc was found to be rate-limiting. This was in contrast to the dehydrogenase reaction of this enzyme where a burst in NADH release was observed, indicating that the rate-limiting step for the dehydrogenase reaction occurs after the formation of the acyl-enzyme intermediate [33].

Lysophospholipase II has previously been shown [8] to catalyze the hydrolysis of $p$-nitrophenylacetate and this hydrolysis was competetively inhibited by 


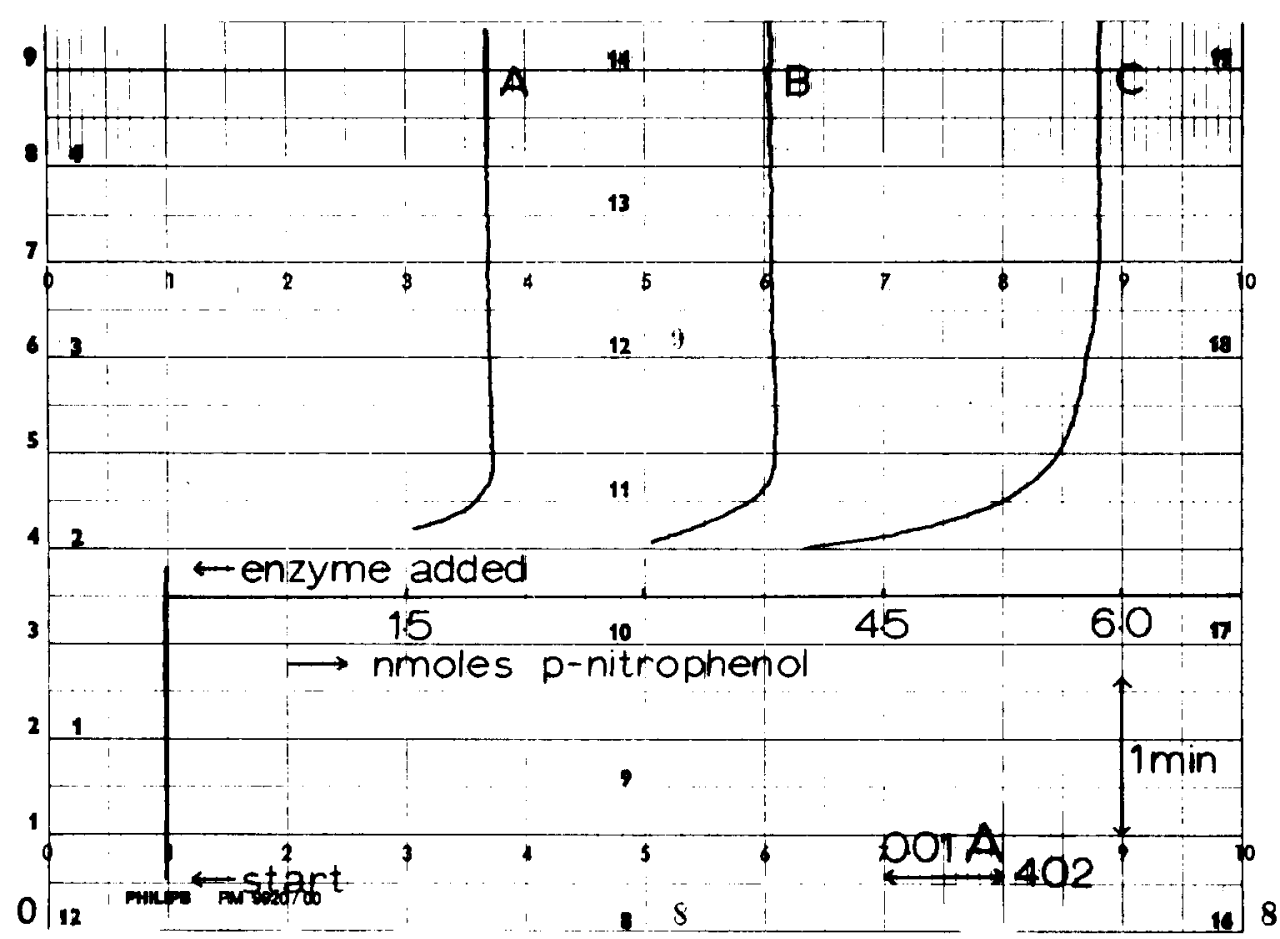

Fig. 5. Titration of lysophospholipase II active sites with bis-(p-nitrophenyl) phosphate. Enzyme (6.5 mg/ ml) was added to $0.5 \mathrm{mM}$ bis-(p-nitrophenyl)phosphate in $100 \mathrm{mM}$ polassium phosphale buffer (pH 7.4 ) to give a final volume of $1 \mathrm{ml}$. A: $130 \mu \mathrm{g}$ enzyme $(2.15 \mathrm{nmol}) ; \mathrm{B}: 260 \mu \mathrm{g}$ enzyme (4.3 nmol) and C: 390 $\mu \mathrm{g}$ enzyme $(6.45 \mathrm{nmol})$. A molar extinction coefficient of $13400 \mathrm{l} \cdot \mathrm{mol}^{-1} \cdot \mathrm{cm}^{-1}$ was used to calculate the amount of $p$-nitrophenol released. Full scale deflection corresponds to $0.1 A_{4} 02$ unit.

1-lauroyl-lysophosphatidylcholine (unpublished experiments). Also a concomitant loss of lysophospholipase and esterase activity in the diisopropylfluorophosphate inhibition studies described in Fig. 3 was noted. This strongly suggests that both substrates were hydrolyzed by a single active site. Attempts to show a burst reaction with $p$-nitrophenylacetate were inconclusive due to too high steady-state hydrolysis rates even when the reaction was carried out at $\mathrm{pH}$ 3.5 and $10^{\circ} \mathrm{C}$. However, given the affinity of the enzyme for $p$-nitrophenyl esters, it should be possible to show burst kinetics with a substrate for which the deacylation is rate-limiting. Although this cannot be achieved with acyl esters, it can be accomplished with phosphate esters for which, by analogy to deacylation, the dephosphorylation is essential zero and hence rate-limiting $[34,35]$. This is shown in Fig. 5 for the hydrolysis of bis( $p$-nitrophenyl)phosphate by lysophospholipase II. A burst-like release of stoichiometric amounts of $p$-nitrophenol is observed. This assay allows for a rapid determination of the amount of active enzyme in highly purified lysophospholipase preparations.

\section{Acknowledgements}

The authors gratefully acknowledge the assistance of Miss G.M. Dingjan, Mr. J.H. Verheijen and Mr. F.A. Kuypers in some of the experiments. Differential scanning calorimetry measurements were made by Dr. P.W.M. van Dijck. 


\section{References}

1 Aarsman, A.J., van Deenen, L.L.M. and van den Bosch, H. (1976) Bioorganic Chem. 5, 241-253

2 Kurooka, S., Okamoto, S. and Hashimoto, M. (1977) J. Biochem. 81, 361-369

3 Aarsman, A.J. and van den Bosch, H. (1977) FEBS Lett. 79, 317-320

4 Aarsman, A.I, Hille, I.D.R. and van den Rosch, H. (1977) Riochim. Biophys. Acta 489, 242-246

5 Baer, E. and Buchnea, D. (1959) Can. J. Biochem. Physiol. 37, 953-959

6 Slotboom, A.J., Verger, R., Verheij, H.M., Baartmans, P.H.M., van Deenen, L.L.M. and de Haas, G.H. (1976) Chem. Phys. Lipids 17, 128-147

7 Yabusaki, K.K. and Wells, M.A. (1973) Biochim. Biophys. Acta 296, 546-548

8 de Jong, J.G.N., van den Bosch, H., Rijken, D, and van Deenen, L.L.M. (1974) Biochim. Biophys. Acta 369, 50-63

9 Grassetti, D.R. and Murray, J.R. Jr. (1967) Arch. Biochem. Biophys. 119, 41-49

10 Chen, P.S., Toribara, T.Y. and Warner, H. (1956) Anal. Chem. 28, 1756-1758

11 Ames, B.N, and Dubin, D.T. (1960) J. Biol. Chem. 235, 769-775

12 Elworthy, P.H. and Mysels, K.J. (1966) J. Colloid Sci. 21, 331-347

13 van Dijck, F.W.M., Ververgaert, P.H.J.Th., Verkleij, A.J., van Deenen, L.L.M. and de Gier, J. (1975) Biochim. Biophys. Acta $406,465-478$

14 Dittmer, J.D. and Lester, R.L. (1964) J. Lipid Res. 5, 126-127

15 Klopfenstein, W.E., de Kruijff, B., Verkleij, A.J., Demel, R.A. and van Deenen, L.L.M. (1974) Chem. Phys. Lipids 13, 215-222

16 Stoffel, W., Metz, P. and Tunggal, B. (1978) Hoppe Seyler's Z. Physiol. Chem. 359, 465-472

17 Haberland, M.E. and Reynolds, J.A. (1975) J. Biol. Chem. 250, 6636-6639

18 Leibovitz-BenGershon, Z., Kobiler, I, and Gatt, S. (1972) J. Biol. Chem. 247, $6840-6847$

19 Bonsen, P.P.M., de Haas, G.H., Pieterson, W.A, and van Deenen, L.L.M. (1972) Biochim. Biophys. Acta $270,364-382$

20 Lewis, M.S. and Gottlieb, M.H. (1971) Abstracts of the 62nd Annual Meeting Federation of American Societies for Experimental Biology, San Francisco, No. 1459

21 de Haas, G.H., Postema, N.M., Nieuwenhuizen, W. and van Deenen, L. L.M. (1968) Biochim. Biophys. Acta $159,103-117$

22 Krupka, R.M. (1964) Biochemistry 3, 1749--1754

23 Ingles, D.W. and Knowles, J.R. (1966) Biochem. J. 99, 275-282

24 Hirohara, H., Bender, M.L. and Stark, R.S. (1974) Proc. Natl. Acad. Sci. U.S. 71, 1643-1647

25 Frankfater, A. and Kézdy, F.J. (1971) J. Am. Chem. Soc. 93, 4039-4043

26 Glaser, C.B., Maeda, H. and Meienhofer, J. (1970) J. Chromatogr. 5U, 151-154

27 Bligh, E.G. and Dyer, W.J. (1959) Can. J. Biochem. Physiol. 37, $911 \rightarrow 918$

28 Wells, M.A. (1971) Biochim. Biophys. Acta 248, 80-86

29 Hartley, B.S. and Kilby, B.A. (1954) Biochem, J, 56, 288-297

30 Chapus, C., Sémériva, M., Bovier-Lapierre, C. and Desnuelle, P. (1976) Biochemistry 15, 4980-4987

31 Kézdy, F.J. and Bender, M.L. (1962) Biochemistry 1, 1097-1106

32 Zerner, B. and Bender, M.L. (1963) J. Am. Chem. Soc. 85, 356-358

33 Weiner, H., Hu, J.H.J. and Sanny, C.G. (1976) J. Biol. Chem. 251, 3853-3855

34 Krisch, K, (1966) Biochim. Biophys. Acta 122, 265-280

35 Krisch, K. (1970) Z. Klin. Chem. Klin. Biochem. 8, 545-551 